Olivet Nazarene University

Digital Commons@ Olivet

Faculty Scholarship - Chemistry

Chemistry

$8-1-2004$

\title{
Pyrrole Syntheses Based on Titanium-Catalyzed Hydroamination of Diynes
}

Douglas Armstrong

Olivet Nazarene University, darmstrg@olivet.edu

Balasubramanian Ramanathan

Adam J. Keith

Aaron L. Odom

Michigan State University, odom@cem.msu.edu

Follow this and additional works at: https://digitalcommons.olivet.edu/chem_facp

Part of the Organic Chemistry Commons

\section{Recommended Citation}

Ramanathan, Balasubramanian, Adam J. Keith, Douglas Armstrong, and Adam L. Odom. "Pyrrole Syntheses Based on TitaniumCatalyzed Hydroamination of Diynes." Organic Letters 6.17 (2004): 2957-2960.

This Article is brought to you for free and open access by the Chemistry at Digital Commons @ Olivet. It has been accepted for inclusion in Faculty Scholarship - Chemistry by an authorized administrator of Digital Commons @ Olivet. For more information, please contact

digitalcommons@olivet.edu. 

Diynes

\author{
Balasubramanian Ramanathan, Adam J. Keith, Douglas Armstrong, and \\ Aaron L. Odom*
}

Department of Chemistry, Michigan State University, East Lansing, Michigan 48824

odom@cem.msu.edu

Received June 10, 2004

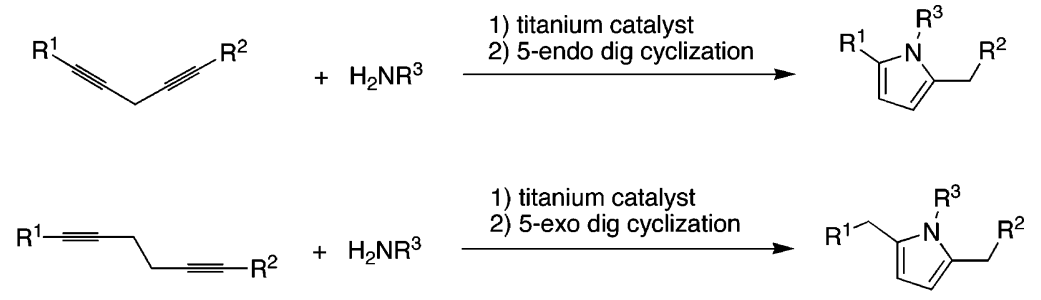

Titanium-catalyzed hydroamination of 1,4- and 1,5-diynes by primary amines leads to imino-alkynes that undergo in situ 5-endo dig and 5-exo dig cyclization reactions, respectively. The products are 1,2,5-trisubsituted pyrroles accessed directly from readily available diyne starting materials.

New synthetic strategies for the generation of substituted pyrroles are of continuous interest due to the ubiquity of this heterocycle in natural products and pharmaceuticals. ${ }^{1}$ We have been exploring new reactions based on titaniumcatalyzed intermolecular hydroamination ${ }^{2,3}$ using a selection of pyrrolyl-based ancillary ligands. In the course of previous studies, new protocols for the synthesis of hydrazones, indoles, ${ }^{4,5}$ and $\alpha, \beta$-unsaturated iminoamines ${ }^{6}$ have been discovered. In this paper, it is reported that the readily

(1) For reviews see: (a) Gilchrist, T. L. J. Chem. Soc., Perkin Trans. 1 1999, 2849-2866. (b) Jones, R. A., Ed. Pyrroles, Chemistry of Heterocyclic Compounds; Wiley: New York, 1990; Vol. 48.

(2) For an excellent review on hydroamination, see: Müller, T. E.; Beller, M. Chem. Rev. 1998, 98, 675-703.

(3) For a few recent examples, see: (a) Shi, Y.; Ciszewski, J. T.; Odom A. L. Organometallics 2001, 20, 3967-3969. (b) Li, C.; Thomson, R. K. Gillon, B.; Patrick, B. O.; Schafer, L. L. Chem. Commun. 2003, 24622463. (c) Siebeneicher, H.; Bytschkov, I.; Doye, S. 2003, 42, 3042-3044. (d) Castro, I. G.; Tillack, A.; Hartung, C. G.; Beller, M. Tetrahedron Lett. 2003, 44, 3217-3221. (e) Ong, T.-G.; Yap, G. P. A.; Richeson, D. S. J. Am. Chem. Soc. 2003, 125, 8100-8101. (f) Ackermann, L.; Bergman, R. G.; Loy, R. N. J. Am. Chem. Soc. 2003, 125, 11956-11963.

(4) Cao, C.; Shi, Y.; Odom, A. L. Org. Lett. 2003, 4, 2853-2856.

(5) Khedkar, V.; Tillack, A.; Michalik, M.; Beller, M. Tetrahedron Lett 2004, 45, 3123-3126.

(6) Cao, C.; Shi, Y.; Odom, A. L. J. Am. Chem. Soc. 2003, 125, 28802881 . prepared, inexpensive titanium catalysts $\mathrm{Ti}\left(\mathrm{NMe}_{2}\right)_{2}(\mathrm{dpma})$ (A) and $\mathrm{Ti}\left(\mathrm{NMe}_{2}\right)_{2}(\mathrm{dmpm})$ (B) (Scheme 1) can be used in the monohydroamination of 1,4- and 1,5-diynes, which then undergo cyclization to the corresponding pyrroles. These pyrrole syntheses are an expansion of CuCl-catalyzed 1,3diyne reactions with primary amines to generate similar products. ${ }^{7}$

The pyrrolyl-based catalyst $\mathrm{Ti}\left(\mathrm{NMe}_{2}\right)_{2}(\mathrm{dpma})(\mathbf{A}),{ }^{8,9}$ which has an $\mathrm{X}_{2} \mathrm{~L}$ ancillary ligand ${ }^{10}$ set (Scheme 1 ), has been examined for a variety of hydroamination applications by our group. The $\mathrm{H}_{2}$ dpma ligand is prepared in a single step by a Mannich reaction between 2 equiv of pyrrole, 2 equiv of formaldehyde, and methylamine hydrochloride. ${ }^{11}$ The most active catalyst known to date is the dipyrrolylmethane

(7) For examples, see: (a) Chalk, A. J. Tetrahedron Lett. 1972, 13, 34873490. (b) Chalk, A. J. Tetrahedron 1974, 30, 1387-1391. (c) Schulte, K E.; Reisch, J.; Walker, H. Chem. Ber. 1965, 98, 98-103. Also, see pages $222-223$ of Part 1 in ref $1 \mathrm{~b}$.

(8) Cao, C.; Ciszewski, J. T.; Odom, A. L. Organometallics 2001, 20 , $5011-5013$

(9) Harris, S. A.; Ciszewski, J. T.; Odom, A. L. Inorg. Chem. 2001, 40, $1987-1988$

(10) Green, M. L. H. J. Organomet. Chem. 1995, 500, 127-148.

(11) Li, Y.; Turnas, A.; Ciszewski, J. T.; Odom, A. L. Inorg. Chem. 2002, 41, 6298-6306. 
Scheme 1
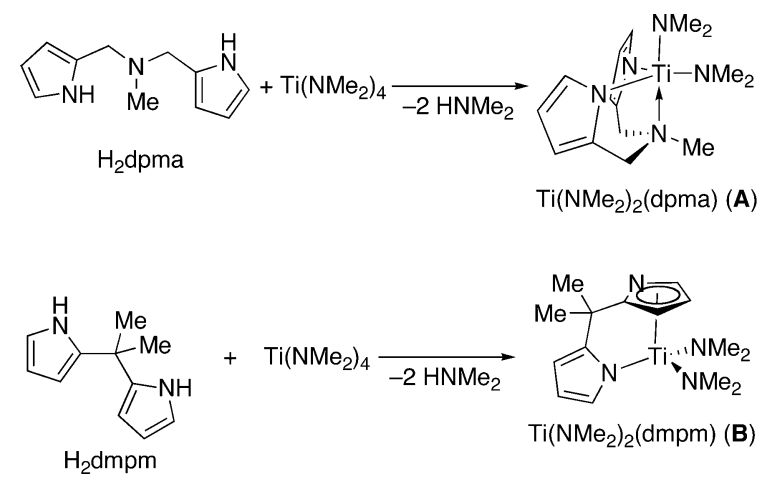

complex $\mathrm{Ti}\left(\mathrm{NMe}_{2}\right)_{2}(\mathrm{dmpm})(\mathbf{B})$, which is useful for more demanding substrate combinations. Catalyst B (Scheme 1) is believed to have an active species that has an $\eta^{1}, \eta^{1}$-dmpm. The $\eta^{5}, \eta^{1}$-dmpm structure, where dmpm refers to 5,5dimethyldipyrrolylmethane, is found in the solid-state for the complex. ${ }^{12}$ In other words, the active species may be an $\mathrm{X}_{2}$ ancillary ligand set. The $\mathrm{H}_{2} \mathrm{dmpm}$ ligand is readily prepared by condensation of acetone and pyrrole. ${ }^{13}$

Initial investigations were based on the known cyclization of imino alkynes to pyrroles. ${ }^{14-16}$ The intended reaction types are illustrated in Scheme 2. Using a 1,4-diyne, monohydroamination with Markovnikov selectivity would yield the 4-iminoalkyne, which could undergo 5-endo dig cyclization ${ }^{17}$ to the pyrrole. Similarly, Markovnikov addition of a primary

(12) Shi, Y.; Hall, C.; Ciszewski, J. T.; Cao, C.; Odom, A. L. Chem. Commun. 2003, 586-587.

(13) Littler, B. J.; Miller, M. A.; Hung, C.-H.; Wagner, R. W.; O’Shea, D. F.; Boyle, P. D.; Lindsey, J. S. J. Org. Chem. 1999, 64, 1391-1396.

(14) For recent examples of pyrrole syntheses from imino alkynes, see: (a) Cossy, J.; Poitevin, C.; Sallé, L.; Pardo, D. G. Tetrahedron Lett. 1996, 37, 6709-6710. (b) Tarasova, O. A.; Nedolya, N. A.; Vvedensky, V. Y.; Brandsma, L.; Trofimov, B. A. Tetrahedron Lett. 1997, 38, 7241-7242. (c) Arcadi, A.; Anacardio, R.; D’Anniballe, G.; Gentile, M. Synlett 1997, 1315-1317. (d) Knight, D. W.; Redfern, A. L.; Gilmore, J. Chem. Commun. 1998, 2207-2208. (e) Le, C.-F.; Yang, L.-M.; Hwu, T.-Y.; Feng, A.-S.; Tseng, J.-C.; Luh, T.-Y. J. Am. Chem. Soc. 2000, 122, 4992-4993. (f) Gabriele, B.; Salerno, G.; Fazio, A.; Bossio, M. R. Tetrahedron Lett. 2001 42, 1339-1341. (g) Kim, J. T.; Gevorgyan, V. Org. Lett. 2002, 4, 46974699.

(15) Similar cyclizations have been explored in indole synthesis. For examples, see: (a) Fujiwara, J.; Fukutani, Y.; Sano, H.; Maruoka, K.; Yamamoto, H. J. Am. Chem. Soc. 1983, 105, 7177-7179. (b) Rudisill, D. E.; Stille, J. K. J. Org. Chem. 1989, 54, 5856-5866. (c) Larock, R. C.; Yum, E. K. J. Am. Chem. Soc. 1991, 113, 6689-6690. (d) Kuyper, L. F.; Baccanari, D. P.; Jones, M. L.; Hunter, R. H.; Tansik, R. L.; Joyner, S. S.; Boytos, C. M.; Rudolph, S. K.; Knick, V.; Wilson, H. R.; Caddell, J. M.; Friedman, H. S.; Comley, J. C. W.; Stables, J. N. J. Med. Chem. 1996, 39, 892-903. (e) McDonald, F. E.; Chatterjee, A. K. Tetrahedron Lett. 1997, 38, 7687-7690. (f) Larock, R. C.; Yam, E. K.; Refvik, M. D. J. Org. Chem. 1998, 63, 7652-7662. (g) Xu, L.; Lewis, I. R.; Davidsen, S. K.; Summers, J. B. Tetrahedron Lett. 1998, 39, 5159-5162. (h) Yasuhara, A.; Kanamori, Y.; Kaneko, M.; Numata, A.; Kondo, Y.; Sakamoto, T. J. Chem. Soc., Perkin Trans. 1 1999, 529-534. (i) Hiroya, K.; Itoh, S.; Ozawa, M.; Kanamori, Y.; Sakamoto, T. Tetrahedron Lett. 2002, 43, 1277-1280. (j) Battistuzzi, G.; Cacchi, S.; Fabrizi, G.; Marinelli, F.; Parisi, L. M. Org. Lett. 2002, 4, 1355-1358. (k) Kamijo, S.; Jin, T.; Yamamoto, Y. Angew. Chem., Int. Ed. 2002, 41, 1780-1782. (1) Barluenga, J.; Trincado, M.; Rubio, E.; Gonzalez, J. M. Angew. Chem., Int. Ed. 2003, 42, 2406-2409. (m) van Esseveldt, B. C. J.; van Delft, F. L.; de Gelder, R.; Rutjes, F. P. J. T. Org. Lett. 2003, 5, 1717-1720.

(16) Kel'in, A. V.; Sromek, A. W.; Gevorgyan, V. J. Am. Chem. Soc. 2001, 123, 2074-2075.

(17) Baldwin, J. E.; Lusch, M. J. Tetrahedron 1982, 38, 2939-2947.
Scheme 2

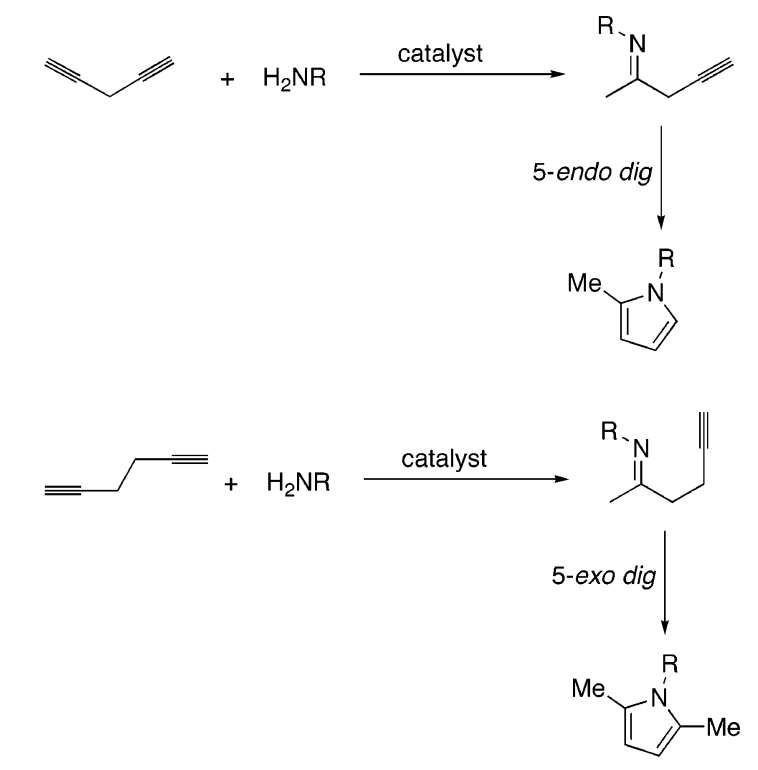

amine to a 1,5-diyne would generate a 5-iminoalkyne, which could undergo 5-exo dig cyclization.

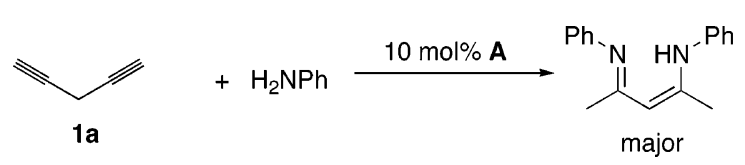

An attempt to carry out the monohydroamination of 1,4pentadiyne (1a) with 1 equiv of aniline was pursued using A as a catalyst. ${ }^{18}$ The major product in the reaction had a mass consistent with double hydroamination of pentadiyne. ${ }^{19,20}$ Data for the dihydroamination product matched that for an authentic sample of 2,4-bis(phenylimino)pentane (eq 1). This result suggests that the second hydroamination is faster than either the first hydroamination or the 5-endo dig cyclization.

It has been shown that hydroamination reactions catalyzed by titanium are sensitive to the size of the alkyne substrate. ${ }^{4}$ Consequently, use of one internal alkyne and one terminal alkyne, or two internal alkynes on the 1,4-pentadiyne framework, should significantly slow the second hydroamination reaction relative to the 5-endo dig cyclization. As shown in Table 1, this strategy has been successful and allowed the synthesis of substituted pyrroles from 1,4-diynes. For this initial study, benzylamine $\left(\mathrm{H}_{2} \mathrm{NBn}\right)$ and aniline were used most often as the amine substrates. An additional reaction with $p$-methoxybenzylamine $\left(\mathrm{H}_{2} \mathrm{NPMB}\right)$ was investigated with one substrate.

Markovnikov addition is observed almost exclusively with A as a catalyst when either benzylamine or aniline are used

(18) Trace of a product having a mass consistent with monohydroamination was observed, but it is not known if it was cyclized to the pyrrole.

(19) For the synthesis of 1,4-diynes, see: Verkruijsse, H. D.; Hasselaar, M. Synthesis 1979, 292-293.

(20) CAUTION: The starting materials for 1,4-diynes used in ref 19 are the propargyl tosylates. Explosions have resulted from purifying propargyl tosylate and its derivatives by vacuum distillation. 
Table 1. Examples of Pyrroles Synthesized by Diyne Hydroamination

\begin{tabular}{|c|c|c|c|c|}
\hline & diyne & amine & $\begin{array}{c}\text { conditions }^{\mathrm{a}} \\
\text { (\%yield) }\end{array}$ & product $^{\mathrm{b}, \mathrm{c}}$ \\
\hline 1 & $\mathrm{Bu}_{\mathbf{1}}^{\mathrm{n}}$ & $\mathrm{H}_{2} \mathrm{NPh}$ & $\begin{array}{c}\mathrm{A}, 24 \mathrm{~h} \\
(56)\end{array}$ & $3 \mathbf{a}$ \\
\hline 2 & & $\mathrm{H}_{2} \mathrm{NBn}^{\mathrm{b}}$ & $\begin{array}{c}\text { A, } 48 \mathrm{~h} \\
\quad(35)\end{array}$ & \\
\hline 3 & $1 \mathrm{c}$ & $\mathrm{H}_{2} \mathrm{NPh}$ & $\begin{array}{c}\mathrm{B}, 30 \mathrm{~h}^{\mathrm{d}} \\
(62)\end{array}$ & $\mathrm{Me}$ \\
\hline 4 & & $\mathrm{H}_{2} \mathrm{NBn}^{\mathrm{b}}$ & $\begin{array}{c}\text { B, 30h } \\
(53)\end{array}$ & $\mathrm{Me}$ \\
\hline 5 & & $\mathrm{H}_{2} \mathrm{NPMB}^{\mathrm{c}}$ & $\begin{array}{c}\text { B, 26h } \\
(30)\end{array}$ & PMB \\
\hline 6 & $\mathrm{H}=\underbrace{}_{\mathbf{2} \mathbf{a}}$ & $\mathrm{H}_{2} \mathrm{NPh}$ & $\begin{array}{c}\mathrm{A}, 75^{\circ} \mathrm{C}, \\
6 \mathrm{~h},(68)\end{array}$ & Me \\
\hline 7 & & $\mathrm{H}_{2} \mathrm{NBn}^{\mathrm{b}}$ & $\begin{array}{c}\mathrm{A}, 14 \mathrm{~h} \\
(34)\end{array}$ & Me \\
\hline 8 & $\mathrm{Ph}=$ & $\mathrm{H}_{2} \mathrm{NPh}$ & $\begin{array}{c}\mathrm{B}, 150{ }^{\circ} \mathrm{C}, \\
26 \mathrm{~h}(90)\end{array}$ & $\mathrm{Bn}$ \\
\hline
\end{tabular}

to hydroaminate 1 -hexyne. ${ }^{8}$ Considering that the terminal alkynes used here are not very sterically or electronically different from 1-hexyne, the major product expected and observed in all cases where a terminal alkyne was present is due to Markovnikov addition.

The anticipated 5-endo dig cyclization occurred readily with most 1,4-diyne substrates to generate pyrrole products. In many cases, a product with the same mass as the expected pyrrole and a different GC/MS retention time was observed, which was presumably the uncyclized hydroamination product.

When hydroamination of the unsymmetrical bis(internal)diyne 1-phenyl-1,4-hexadiyne (1c) was attempted, entries $3-5$ in Table 1 , the reactions were apparently regioselective and resulted in only one isomer of pyrrole. This is likely due to selective hydroamination of the phenyl-bearing alkyne. Hydroamination of similar substrates, e.g., 1-phenylpropyne, occurs with amination $\beta$ to the phenyl group, which is consistent with the observed regioselectivity for this diyne substrate. In addition, hydroamination of 1-phenylpropyne is generally more facile than hydroamination of dialkyl substituted alkynes, e.g., 3-hexyne. Consequently, it is likely that the regioselectivity for this substrate is due to kinetically favored amination $\beta$ to the phenyl group of 1-phenyl-1,4hexadiyne (1c).

The titanium-based pyrrole synthesis of $\mathbf{3 d}$ provides an interesting example for comparison with current and progressing ketone-based methodologies, e.g., Paal-Knorr synthesis. Generally, unsymmetrical 1,4-diketones are relatively difficult to access in a short synthetic sequence. However, the diketone needed for the synthesis of $\mathbf{3 d}$ by Paal-Knorr and its reaction with benzylamine were recently reported. ${ }^{21}$ The diketone was prepared using a novel Pdcatalyzed procedure from methyl vinyl ketone and benzylzinc chloride. Overall, $\mathbf{3 d}$ was available in $54 \%$ yield over two steps. Using the procedure of Verkruijsse to generate the diyne and titanium hydroamination, we prepared the unsymmetrical pyrrole $\mathbf{3 d}$ in the comparable yield of $41 \%$ in two steps.

The cyclization of the imine derived from 1-phenyl-1,4hexadiyne (1c) was quite slow after the titanium-catalyzed reaction when the amine substrate was aniline. To finish the cyclization, Gevorgyan's procedure using $30 \mathrm{~mol} \% \mathrm{CuI}$ in the presence of triethylamine at $110^{\circ} \mathrm{C}$ was employed prior to workup. ${ }^{16}$ Interestingly, the addition of copper for the cyclization was only required for 1-phenyl-2-benzyl-5methylpyrrole (3c) formation. The benzylamine and paramethoxybenzylamine $\left(\mathrm{PMB}-\mathrm{NH}_{2}\right.$ ) products (entries 4 and 5 ) cyclized under the hydroamination reaction conditions to provide $N$-benzyl-2-benzyl-5-methylpyrrole (3d) and $N$-PMB2-benzyl-5-methylpyrrole (3e).

Unlike 1,4-pentadiyne (1a), hydroamination of 1,5-hexadiyne (2a), which also has both alkynes terminal, did not yield products from dihydroamination. Instead, the products observed are the expected $\mathrm{N}$-substituted 2,5-dimethylpyrroles (3f and 3g). ${ }^{22}$ This is likely due to the more facile 5-exo dig cyclization being faster than the hydroamination reaction. Unlike the 1,4-diyne hydroaminations, no uncyclized products were observed by GC under the reaction conditions.

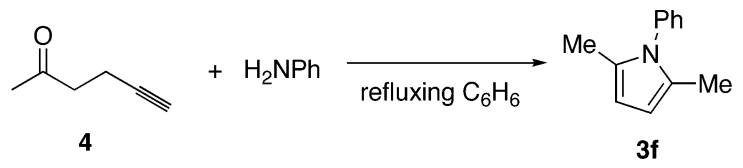

Even though the imine product was not observed in the hydroamination of 1,5 -hexadiyne (2a), it is still likely that the imine is an intermediate. The relevant ketone derivative of this intermediate, hex-5-yn-2-one (4), was prepared

(21) Yuguchi, M.; Tokuda, M.; Orito, K. J. Org. Chem. 2004, 69, $908-$ 914.

(22) The same symmetrical pyrroles, $\mathbf{3} \mathbf{f}$ and $\mathbf{3 g}$, have been generated using Paal-Knorr synthesis and reported repeatedly in the literature. In typical examples, $\mathbf{3 f}$ and $\mathbf{3 g}$ were synthesized in 82 and $67 \%$ yields, respectively. Wothius, E.; Vander Jagt, D.; Mels, S.; De Boer, A. J. Org. Chem. 1965, 30, 190-193. 
according to the literature procedure. ${ }^{23}$ Reaction of the ketone with aniline (eq 2) in the absence of titanium leads to formation of $N$-phenyl-2,5-dimethylpyrrole (3f) that is spectroscopically identical to the product of $\mathbf{2 a}$ hydroamination with aniline.

As mentioned previously, if the alkyne is substituted with one aryl group and one alkyl, the predominant product is generally due to amination $\beta$ to the aromatic substituent. Likewise, hydroamination of 1,6-diphenyl-1,5-hexadiyne (2b) ${ }^{24}$ with aniline resulted in clean, high-yield formation of a single isomer, $N$-phenyl-2,5-dibenzylpyrrole (3h). ${ }^{25}$

A few substrate combinations attempted did not result in successful pyrrole syntheses. Treatment of 1,6-diphenyl-1,5hexadiyne (2b) with benzylamine gave no reaction with catalysts $\mathbf{A}$ and $\mathbf{B}$. Considering the harsh conditions required for the aniline reaction with this diyne and that aniline reactions are generally more facile than alkylamine, the lack of reaction with benzylamine probably represents a limitation in the activity of our current catalysts rather than an inherent problem with the substrate combination. In addition, 1-phenyl-1,4-pentadiyne (1d) reactions with either aryl or alkylamines (Equation 3) did not give the desired product, which may be the result of facile oligomerization of this diyne starting material.

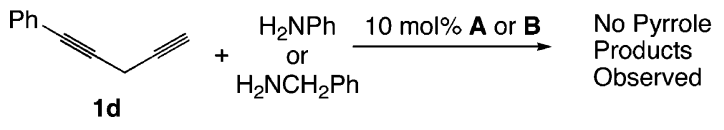

The cyclizations could occur though several different routes defined by disparate tautomers. However, the cyclizations are likely occurring through the Baldwin allowed 5-endo dig and 5-exo dig cyclizations, and it is unlikely that allene intermediates are involved. The reason for this is that the 5-endo trig and 5-exo trig cyclizations ${ }^{17}$ required for the

(23) Davis, L. B.; Greenberg, S. G.; Sammes, P. G. J. Chem. Soc., Perkin Trans. 1 1981, 1909-1912.

(24) Lucht, B. L.; Mao, S. S. H.; Tilley, T. D. J. Am. Chem. Soc. 1998, $120,4354-4365$.

(25) Pyrrole 3h did not appear in our literature searches. However, a comparison can be made with 1,2,5-tribenzylpyrrole, which has been synthesized using Paal-Knorr in three steps from commercially available compounds in $42 \%$ yield overall. Wilcox, A. L.; Bao, Y. T.; Loeppky, R. N. Chem. Res. Toxicol. 1991, 4, 373-381. Our synthesis of $\mathbf{3 h}$ was accomplished in $61 \%$ overall yield in two steps. allene intermediates are disfavored. ${ }^{26}$ Experimentally, it has been shown that 1-imino-2-alkynes require copper catalysis to cyclize, which has been suggested to occur through allene intermediates. ${ }^{16}$ Consequently, we currently favor either an imine-yne or enamine-yne cyclization pathway for 1-imino3-ynes. However, these details of the cyclizations are currently under scrutiny, including the possible role of titanium in the cyclizations.

Applications of this new pyrrole synthesis based on alkyne hydroamination are currently under investigation. While Paal-Knorr is likely to be the preferable methodology in circumstances where the 1,4-diketone is readily available, it is hoped that this new pyrrole synthesis will complement existing procedures where unsymmetrical pyrroles are desired. Many unsymmetrical 1,4-diynes can be prepared in one or two steps from commercially available compounds and may be as or more accessible than the corresponding unsymmetrical 1,4-diketones in some cases. In addition, we are investigating the use of this new methodology in the synthesis of pyrroles where application of Paal-Knorr synthesis may lead to unwanted side reactions. For example, we are investigating the synthesis of $\alpha$-vinylpyrroles using diyne hydroamination, which if prepared using $\alpha, \beta$-unsaturated ketones may have problems with interfering Michaeladdition side reactions. ${ }^{27}$

Acknowledgment. The authors appreciate the financial support of the donors of the Petroleum Research Fund, administered by the American Chemical Society, the Office of Naval Research, the National Science Foundation, and the Department of Energy-Defense Programs. A.L.O. is an Alfred P. Sloan Fellow. The authors thank Bill Wulff for helpful discussions.

Supporting Information Available: Synthetic details and characterization data. This material is available free of charge via the Internet at http://pubs.acs.org.

\section{OL0489088}

(26) Some 5-endo trig cyclizations are known. These often involve metalmediated processes. For examples, see: (a) Trost, B. M.; Bonk, P. J. J. Am. Chem. Soc. 1985, 107, 1778-1781. (b) Auvray, P.; Knochel, P.; Normant, J. F. Tetrahedron Lett. 1985, 26, 4455-4458. Also see ref 16

(27) To generate an $\alpha$-vinyl pyrrole using Paal-Knorr synthesis would require reaction of an $\alpha, \beta$-unsaturated ketone with an amine to generate the corresponding imine, a reaction that is often complicated by competing Michael addition. Hydroamination of the enyne can be used as an alternative procedure to $\alpha, \beta$-unsaturated imines. Cao, C.; Li, Y.; Shi, Y.; Odom, A. L. Chem. Commun. In press. 